\title{
Analisa Penggunaan WebRTC dan Websocket pada Real Time Multiplayer Online Game Tradisional Ceki
}

\author{
Gede Humaswara Prathama ${ }^{1}$, Ni Made Ary Esta Dewi Wirastuti ${ }^{2}$, Yoga Divayana ${ }^{3}$ \\ [Submission: 23-11-2018, Accepted: 31-03-2019]
}

\begin{abstract}
Ceki is one of the traditional card games that has been quite popular in Malaysia, Singapore and Indonesia. In Bali the game of ceki has become a tradition, where the game is played when there is community activity. Multiplayer online games are one way to introduce and develop traditional games to be more interesting to play. The problems that are often faced to develop multiplayer online games include the latency problems that are different from each player so that it can interfere with games from other players who have better latency. In this study, a real time multiplayer online game will be built to play traditional games. discussing how the rules of traditional games obtained from the rules of the Balinese game will be applied to the game engine from online multiplayer games, how to implement online game multiplayer architecture on client-server and peer to peer web-browsers. The focus of this research is on the performance of the use of websocket and webRTC on latency for data synchronization that supports real time multiplayer online games based on peer to peer connection. From the average latency needed for data synchronization between web socket compared to webRTC, it can be concluded that the use of webRTC has a very significant effect on latency. The number of players has no effect on latency both on websocket and webRTC
\end{abstract}

Intisari-Ceki adalah salah satu permainan kartu tradisional yang pernah cukup popular di Malaysia, Singapura dan Indonesia. Di Bali permainan ceki sudah menjadi tradisi, dimana permainan ceki dimainkan saat adanya kegiatan masyarakat. Multiplayer online games adalah salah satu cara untuk mengenalkan dan mengembangkan games tradisional menjadi lebih menarik untuk dimainkan. Permasalahan yang sering dihadapi untuk mengembangkan multiplayer online game diantaranya adalah permasalahan latency yang berbeda dari masing-masing pemain sehingga bisa mengganggu permainan dari pemain lain yang memiliki latency lebih baik. Pada penelitian ini akan dibangun real time multiplayer online game untuk memainkan permainan tradisional ceki, menganalisa tentang bagaimana aturan-aturan dari permainan tradisional ceki yang didapat dari aturan permainan masyarakat Bali akan diterapkan pada game engine dari multiplayer online game, bagaimana implementasi arsitektur multiplayer online game pada web-browser yang berbasis client-server dan peer to peer. Fokus dari penelitian ini adalah pada performansi dari penggunaan websocket dan webRTC terhadap latency pada sinkronisasi data yang mendukung real time multiplayer online game berbasis koneksi peer to peer. Dilihat dari rata-rata latency yang dibutuhkan untuk sinkronisasi data antara websocket

${ }^{1}$ Mahasiswa, Jurusan Teknik Elektro dan Komputer Fakultas Teknik Universitas Udayana, Jln. Gatot Subroto II Denpasar 80231 INDONESIA (telp: 081805635084; fax: - ; e-mail: huma.elektro@gmail..com)

${ }^{2,3}$ Dosen, Jurusan Teknik Elektro dan Komputer Fakultas Teknik Universitas Udayana, Jln. Jalan Kampus Bukit Jimbaran 80361 INDONESIA (telp: 0361-703315; fax: 0361-4321; e-mail: dewi.wirastuti@ee.unud..ac.id) yogadivayana@gmail.com) dibandingkan dengan webRTC, dapat disimpulkan bahwa penggunaan webRTC memberikan pengaruh yang sangat signifikan terhadap latency. Jumlah pemain tidak berpengaruh pada latency baik pada websocket maupun webRTC.

Kata Kunci - Ceki, Multiplayer Online Game, websocket, webRTC, latency, web protocol

\section{PENDAHULUAN}

Games atau permainan telah menjadi bagian hidup bagi masyarakat sejak dahulu, baik hanya sebagai hiburan hingga menjadi mata pencaharian. Games atau permainan yang ada saat ini juga banyak dipengaruhi oleh budaya (permainan tradisional) dan perkembangan teknologi. Saat ini permainan yang berbasis teknologi mendominasi di masyarakat dan permainan tradisional mulai ditinggalkan oleh masyarakat, dari permainan yang dimainkan sendiri (Singleplayer) hingga permainan yang bisa dimainkan lebih dari 1 orang (Multiplayer) dan permainan yang dimainkan secara offline hingga permainan yang dimainkan secara online. Tidak sedikit pengembang games saat ini yang mengangkat kembali permainan tradisional yang berbasis teknologi dan terkadang ditambahkan sedikit modifikasi agar games lebih menarik untuk dimainkan. Games tradisional umumnya adalah permainan yang dimainkan oleh lebih dari 1 orang, maka pengembang games diharuskan mengembangkan games yang bisa dimainkan lebih dari 1 orang, berdasarkan rating di layanan penjualan aplikasi, game yang bisa dimainkan dengan teman atau orang lain selain bot lebih diminati oleh masyarakat, hal ini disebabkan karena adanya interaksi sosial yang terjadi jika memainkannya dengan teman atau orang lain dibandingkan dengan bot, maka multiplayer online games adalah salah satu cara untuk mengembangkan games tradisional menjadi lebih menarik untuk dimainkan dengan lebih dari 1 pemain.

Multiplayer online games adalah permainan yang bisa dimainkan oleh lebih dari satu pemain secara online melalui jaringan internet dalam waktu yang sama. Multiplayer online game menjadi menarik karena adanya interaksi sosial yang terjadi dalam permainan yaitu berupa kerja sama, kompetisi hingga persaingan dalam meraih reward pada permainan dengan teman atau orang lain. Secara umum Multiplayer online game memiliki beberapa kategori di antaranya adalah Massively Multiplayer Online game (MMO), Massively Multiplayer Online First-person shooter games (MMOFPS), Massively Multiplayer online Real-time strategy games (MMORTS), Massively Multiplayer Online Role-playing games (MMORPG), Multiplayer Online Battle arena (MOBA). Salah satu jenis multiplayer online games yang cukup popular dimainkan adalah card games, permainan ini menjadi popular karena cara bermain yang sederhana dan tidak sedikit card games yang ada saat ini berasal dari 
permainan tradisional di mana permainan ini sudah ada sebelum adanya teknologi seperti saat ini.

Ceki adalah salah satu permainan kartu tradisional yang pernah cukup popular di Malaysia, Singapura dan Indonesia, namun saat ini permainan ceki sudah mulai jarang dimainkan di Malaysia dan Singapura. Ceki disebutkan berasal dari permainan di negara Tiongkok (Cina kuno) dan disebut juga menurunkan cara permainan tradisional mahjong yang memang sangat popular di Tiongkok hingga saat ini. Ceki dimainkan dengan aturan dan cara memainkan yang berbedabeda di setiap daerah di Indonesia tergantung dari budaya dan tradisi yang ada di daerah tersebut. Di Bali permainan ceki sudah menjadi tradisi, di mana permainan ceki dimainkan saat adanya kegiatan masyarakat atau upacara adat, bahkan saat ini sudah dibuatkan kompetisi permainan ceki oleh pemerintah daerah Bali. Permainan ceki bisa dimainkan oleh $4-5$ pemain namun idealnya dimainkan oleh 5 pemain agar peredaran kartu berputar dengan baik. 1 set kartu Ceki atau yang sering juga disebut dengan Sampian oleh masyarakat bali terdiri dari 60 kartu dan dimainkan dengan 2 set kartu.

Arsitektur multiplayer online games umumnya berbasis client-server, di mana server digunakan sebagai data center, game lobby, game engine dan game room. Protocol yang digunakan sebagai sarana komunikasi antara client dan server adalah $T C P$ atau $U D P$ dengan kelebihan dan kekurangan masing-masing disesuaikan dengan games yang akan dikembangkan, atau bisa juga kombinasi dari TCP dan $U D P$. Untuk mendapatkan kesan real-time pada multiplayer online games, pengembang umumnya melakukan optimalisasi paket menggunakan serialisasi data paket yang dikirim melalui protocol untuk mengurangi latency pada pergerakan pemain yang dilihat oleh pemain lain dalam permainan. Arsitektur Multiplayer online games juga bergantung pada platform yang digunakan untuk mengembangkan games dan tidak jarang games yang dikembangkan bisa dimainkan melalui banyak platform atau yang sering disebut dengan cross-platform. Web-browser adalah salah satu platform atau virtual machine yang digunakan untuk memainkan online games.

Permasalahan yang sering dihadapi untuk mengembangkan multiplayer online games di antaranya adalah permasalahan latency yang berbeda dari masingmasing pemain tergantung dari koneksi internet yang digunakan masing-masing pemain sehingga bisa mengganggu permainan dari pemain lain yang memiliki latency lebih baik. Permasalahan lainnya adalah protokol apa yang sebaiknya digunakan untuk mendapatkan kesan real time dari permainan, bagaimana mengoptimalkan paket data dari client ke server begitu juga sebaliknya, bagaimana jika salah satu atau beberapa pemain kehilangan koneksi sementara dan yang sering menjadi permasalahan adalah penggunaan bandwidth untuk komunikasi data yang tentu saja diharuskan penggunaan bandwidth sekecil mungkin.

Pada penelitian ini akan dibangun real time multiplayer online games untuk memainkan permainan tradisional ceki, menganalisa tentang bagaimana aturan-aturan dari permainan tradisional ceki yang didapat dari aturan permainan masyarakat Bali akan diterapkan pada game engine dari multiplayer online game yang akan dibangun. Bagaimana implementasi arsitektur multiplayer online games pada web-browser yang berbasis client-server dan peer to peer. Fokus dari penelitian ini adalah pada uji performansi dari penggunaan websocket dan webRTC terhadap latency dan penggunaan bandwidth untuk sinkronisasi data yang mendukung real time multiplayer online games berbasis client-server dan peer to peer.

\section{TINJAUAN PUSTAKA}

\section{A. Ceki}

Ceki merupakan sebuah permainan kartu yang mirip dengan permainan di cina. Setiap satu pack terdiri dari 60 kartu (30 jenis bentuk). Jumlah kartu yang dibutuhkan dalam permainan ceki adalah 2 pack kartu dengan masing-masing jumlah bentuk kartu terdiri dari 4 buah pasangan dengan jumlah total 120. Pada permainan ceki jumlah kartu yang dipegang pemain berjumlah 11 lembar. Permainan ceki memiliki beberapa istilah atau aturan dalam memainkannya. Adapun istilah-istilah atau aturan permainan ceki adalah sebagai berikut :

- Mukak merupakan istilah untuk mengambil kartu hasil dari kocokan. Daerah lain di Bali sering menggunakan istilah ngupak.

- Ngejuk merupakan istilah untuk mengambil kartu buangan pemain sebelumnya.

- Ngutang merupakan istilah saat pemain membuang sebuah kartu dari tangan.

- Medua atau lawang merupakan istilah untuk kartu yang dipegang pemain memiliki gambar dan tepi yang sama sebanyak dua lembar.

- Soca merupakan istilah untuk tiga lembar kartu di tangan pemain yang memiliki bentuk tepi dan gambar yang sama.

- Serigat merupakan tiga lembar kartu di tangan yang memiliki bentuk tepi yang sama. Serigat terdiri dari dua jenis, yaitu serigat dua dan serigat telu.

- Mecari merupakan kondisi pemain menunggu kartu terakhir saat pemain sudah mengumpulkan satu soca, dua serigat, dan 1 medua atau lawang.

- Nyaga merupakan kondisi pemain menunggu kartu terakhir setelah mengumpulkan dua soca, satu serigat dan dua medua atau lawang. Kondisi nyaga memiliki aturan setiap pemain yang melakukan "mukak", kartu yang dibuka harus diperlihatkan ke pemain dalam kondisi nyaga.

- Mbet merupakan istilah saat kartu terakhir yang dicari atau dijaga pada proses mecari atau nyaga sudah keluar atau terbuang, sehingga pemain tidak bisa menang.

- Minde merupakan kondisi saat pemain pertama membuang kartu yang sama sebanyak dua kali dan kartu yang dibuang tersebut diambil oleh pemain berikutnya.

\section{B. Permainan Online (Online Games)}

Permainan online atau dialih bahasakan menjadi permainan daring (Online Games) adalah jenis permainan komputer yang memanfaatkan jaringan internet, sebagai medianya. Permainan online disediakan sebagai tambahan layanan dari perusahaan penyedia jasa online, atau dapat diakses langsung melalui sistem yang disediakan dari perusahaan yang menyediakan permainan tersebut [1]. Terdapat banyak pola pada online 
games yang bisa digunakan pengembang games, untuk permainan kartu secara online ada 2 pola yang bisa digunakan yaitu Shadowplayer pattern dan Serverfocused pattern, dimana setiap kali beban server harus rendah dan komputasi pada klien cukup kuat dan para pengguna games terus bertambah, pola desain Shadowplayer harus diterapkan untuk implementasi namun jika beban pada klien harus rendah, kemudian pola desain Serverfocused yang harus diterapkan [2].

\section{Client-server}

Client-server adalah model arsitektur perangkat lunak yang terdiri dari dua bagian, sistem klien dan sistem server, baik berkomunikasi melalui jaringan komputer atau pada komputer yang sama. Aplikasi client-server adalah sistem terdistribusi yang terdiri dari perangkat lunak klien dan server. Aplikasi server klien menyediakan cara yang lebih baik untuk berbagi beban kerja. Pada awal ditemukan arsitektur Clientserver proses klien selalu memulai koneksi ke server, sementara proses server selalu menunggu permintaan dari klien mana pun. Dengan kecepatan internet saat ini aplikasi dengan arsitektur Client-server mulai banyak dikembangkan dengan jumlah klien yang sangat banyak sehingga beban server menjadi sangat besar, ini disebabkan oleh semakin banyak klien yang terhubung pada server, maka rata-rata bytes/detik yang dikirimkan akan semakin besar, begitu juga dengan rata-rata paket/detik dan semakin besar ukuran file yang ditransfer maka akan semakin besar pula throughput-nya sampai mencapai kondisi saturasi sedangkan latency akan semakin cepat jika ukuran paket semakin kecil [3][4].

\section{Websocket}

WebSocket adalah protokol komunikasi komputer, menyediakan saluran komunikasi full duplex melalui koneksi TCP [5][6]. Protokol websocket distandarisasi oleh IETF sebagai RFC 6455 pada tahun 2011. Websocket adalah protokol TCP yang berbeda dari HTTP. Kedua protokol terletak di layer 7 dalam model OSI, dengan demikian websocket bergantung pada TCP pada layer 4. Protokol websocket memungkinkan interaksi antara klien web (seperti browser) dan web server dengan overhead yang lebih rendah, memfasilitasi transfer data real time dari dan ke server. Hal ini dimungkinkan dengan menyediakan cara standar bagi server untuk mengirim konten ke klien tanpa diminta terlebih dahulu oleh klien, dan memungkinkan pesan diteruskan bolak-balik sambil menjaga koneksi tetap terbuka. Protokol websocket saat ini didukung di sebagian besar browser termasuk Google Chrome, Microsoft Edge, Internet Explorer, Firefox, Safari dan Opera [6][7]. Websocket juga membutuhkan aplikasi web di server untuk mendukungnya. Untuk membuat sambungan websocket, klien harus mengirim permintaan handshake websocket, lalu server akan mengembalikan respons handshake websocket, seperti yang ditunjukkan pada contoh di bawah ini [5]:

\section{GET/chat HTTP/1.1}

Host: server.example.com

Upgrade: websocket

Connection: Upgrade

Sec-WebSocket-Key: x3JJHMbDL1EzLkh9GBhXDw==

Gede Humaswara Prathama: Analisa Penggunaan WebRTC dan...
Sec-WebSocket-Protocol: chat, superchat

Sec-WebSocket-Version: 13

Origin: http://example.com

Handshake pada websocket menyerupai HTTP dalam berkomunikasi dengan server untuk menangani koneksi HTTP serta koneksi WebSocket pada port yang sama. Setelah koneksi terbentuk, komunikasi beralih ke protokol biner dua arah yang tidak sesuai dengan protokol HTTP [8]. Selain meng-upgrade header, klien mengirimkan header sec-websocket-key yang berisi byte acak base64-encoded, dan server membalas dengan hash key di header sec-websocket-accept. Ini dimaksudkan untuk mencegah proxy caching mengirim ulang percakapan websocket sebelumnya dan tidak memberikan otentikasi, privasi atau integritas apa pun. Fungsi hashing menambahkan string tetap 258EAFA5-E914-47DA-95CA-C5AB0DC85B11 (sebuah GUID) ke nilai dari header sec-websocket-key (yang tidak didekodekan dari base64), menerapkan fungsi hashing SHA-1, dan mengkodekan hasilnya menggunakan base64. Setelah koneksi terbentuk, klien dan server dapat mengirim data websocket atau teks bolak-balik dalam mode full-duplex.

\section{E. WebRTC}

WebRTC (Web Real Time Communication) adalah proyek sumber terbuka gratis yang menyediakan layanan bagi browser web dan aplikasi seluler dengan real time communication (RTC) melalui antarmuka Application Programming Interface (API). Hal ini memungkinkan komunikasi audio dan video bekerja di dalam halaman web yang memungkinkan komunikasi peer-to-peer, menghilangkan kebutuhan untuk menginstall plugin atau mengunduh aplikasi lain. WebRTC juga dapat mengurangi konsumsi daya dan penggunaan bandwidth dengan demikian webRTC dapat meningkatkan efisiensi sistem [9]. Misinya adalah untuk mengaktifkan aplikasi $R T C$ berkualitas tinggi yang dikembangkan untuk peramban, platform seluler, dan perangkat IoT, dan memungkinkan mereka semua berkomunikasi melalui seperangkat protokol umum. Pembentukan dengan cepat koneksi peer RTC adalah persyaratan penting untuk aplikasi web masa depan. Juga, kinerja transfer media dan data yang baik khususnya pada perangkat seluler, sangat penting untuk mendapatkan pengalaman pengguna yang baik [10]. Referensi implementasi dirilis sebagai perangkat lunak bebas di bawah ketentuan lisensi BSD. Komponen utama dari WebRTC termasuk beberapa API JavaScript adalah:

- getUserMedia, yaitu komponen yang mengakuisisi media audio dan video (misal, dengan mengakses kamera dan mikrofon perangkat) [11].

- RTCPeerConnection memungkinkan komunikasi audio dan video antar sesama. Ini melakukan pemrosesan sinyal, penanganan codec, komunikasi peer-to-peer, keamanan, dan manajemen bandwidth [11].

- RTCDataChannel memungkinkan komunikasi dua arah dari data acak antar sesama yang menggunakan API yang sama dengan websocket dan memiliki latency yang sangat rendah [11].

p-ISSN:1693 - 2951; e-ISSN: 2503-2372 
API WebRTC juga mencakup fungsi statistik:

- getStats memungkinkan aplikasi web untuk mengambil sekumpulan statistik tentang sesi WebRTC. Data statistik ini sedang dijelaskan dalam dokumen $\mathrm{W} 3 \mathrm{C}$ yang terpisah [11].

API PeerConnection, kanal data dan media capture browser dijelaskan secara rinci di W3C. W3C mengembangkan ORTC (Object Real-Time Communications) untuk WebRTC. Ini biasanya disebut sebagai WebRTC 1.1.

\section{Metode PENELITIAN}

Metode penelitian menguraikan beberapa hal antara lain, rancangan penelitian yang terdiri dari gambaran umum, Game server, Gameplay Engine, alur komunikasi data, serialisasi data, rancangan database dan rancangan user interface.

A. Rancangan Penelitian.

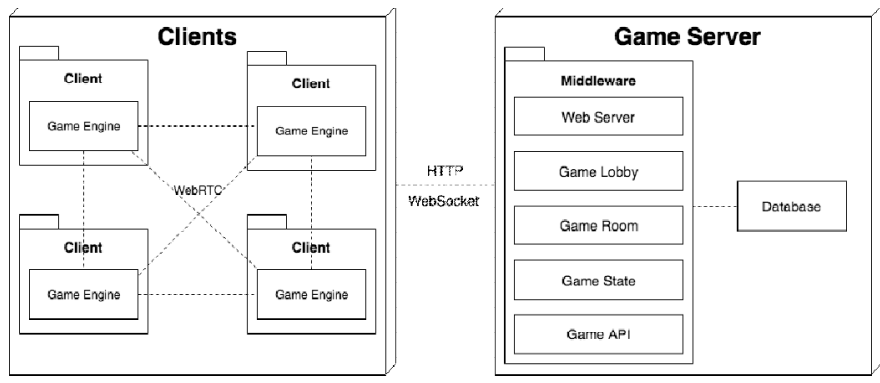

Gambar 1: Gambaran umum sistem

Pada gambaran umum penelitian ini dijelaskan bahwa pola yang digunakan pada sistem ini adalah pola shadow player dimana game engine terletak pada client. Sistem dimulai dari game server dimana game server bertugas hanya untuk mendaftarkan pemain baru, mempersiapkan permainan pada game room, mendistribusikan kartu pada game room dan mencatat histori permainan pada saat permainan berlangsung. Ketika permainan berlangsung proses diserahkan kepada gameplay engine yang ada pada masing-masing client, gameplay engine disini bertugas untuk mengatur permainan mulai dari mengatur giliran pemain, komunikasi data permainan antar client melalui gameplay engine, komunikasi data ke server untuk melaporkan histori permainan dan menentukan hasil permainan jika ada yang menang atau terjadi draw pada permainan sesuai dengan rule yang ada pada gameplay engine. Pada komunikasi data antar client yang dilakukan oleh gameplay engine dilakukan tanpa server (peer to peer). Alur permainan ceki pada penelitian ini disesuaikan dengan permainan yang berlaku pada daerah kabupaten Tabanan dan kabupaten Negara dikarenakan pada beberapa daerah aturan permainan terdapat sedikit perbedaan, berikut adalah flowchart dari gameplay:

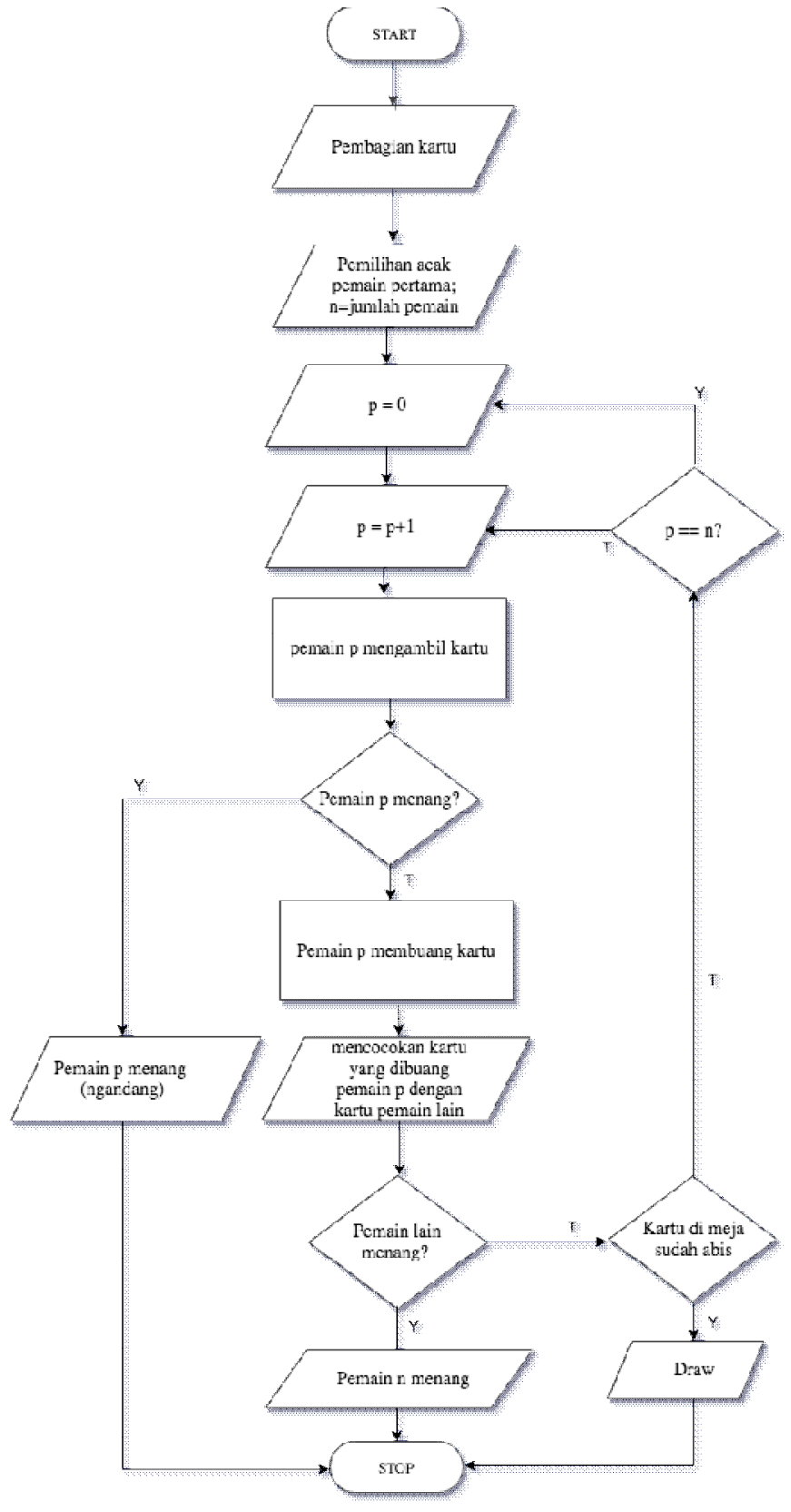

Gambar 2: Diagram alur Permainan Kartu Ceki

Pada penelitian ini menggunakan 2 protokol pada komunikasi data baik pada client to server dan peer to peer. Pada komunikasi client to server digunakan websocket dan HTTP sebagai protokol. Websocket digunakan untuk komunikasi game state pada game room secara real time tanpa perlu melakukan long polling dan HTTP digunakan pada game lobby dimana client melakukan pendaftaran akun, login dan masuk ke dalam game room. Pada komunikasi peer to peer digunakan webRTC sebagai protokol untuk komunikasi peer to peer antar client, diharapkan dengan menggunakan webRTC latency yang didapatkan oleh client sangat kecil. Proses serialisasi data juga dilakukan untuk meminimalkan data paket yang dikirim melalui protokol baik pada client-server dan peer to peer. Pada penelitian ini digunakan jenis serialisasi data yaitu JSON yang dikonversi menjadi arraybuffer ketika dikirim. Rancangan database dibuat dengan tujuan untuk mengidentifikasi kebutuhan file-file database (basis data) yang dibutuhkan 
dalam pembuatan program. Rancangan struktur tabel pada penelitian ini dapat dilihat seperti berikut:

TABEL I

STRUKTUR TABEL PEMAIN

\begin{tabular}{|l|c|l|l|}
\hline \multicolumn{1}{|c|}{ Nama field } & Type & Key & \multicolumn{1}{|c|}{ Keterangan } \\
\hline id_pemain & $\operatorname{int}(9)$ & Pri & Id kode pemain \\
\hline Username & varchar (20) & & Nama unik pemain \\
\hline email & varchar (100) & & Email pemain \\
\hline Password & varchar (100) & & Password pemain \\
\hline Menang & $\operatorname{Int}(9)$ & & $\begin{array}{l}\text { Jumlah kemenangan } \\
\text { pemain }\end{array}$ \\
\hline draw & $\operatorname{Int}(9)$ & & Jumlah draw pemain \\
\hline kalah & $\operatorname{Int}(9)$ & & $\begin{array}{l}\text { Jumlah kekalahan } \\
\text { pemain }\end{array}$ \\
\hline
\end{tabular}

TABEL II

STRUKTUR TABEL GAME_ROOM

\begin{tabular}{|l|c|c|l|}
\hline Nama field & Type & Key & Keterangan \\
\hline id_room & int (9) & Pri & $\begin{array}{l}\text { uid game } \\
\text { room }\end{array}$ \\
\hline mulai & datetime () & & $\begin{array}{l}\text { Waktu saat } \\
\text { permainan } \\
\text { dimulai }\end{array}$ \\
\hline selesai & datetime () & & $\begin{array}{l}\text { Waktu saat } \\
\text { permainan } \\
\text { selesai }\end{array}$ \\
\hline game_state & longtext & & $\begin{array}{l}\text { Histori } \\
\text { permainan } \\
\text { berupa JSON } \\
\text { yang di } \\
\text { convert } \\
\text { menjadi string }\end{array}$ \\
\hline
\end{tabular}

TABEL III

STRUKTUR TABEL GAME_ROOM_PLAYER

\begin{tabular}{|l|c|c|l|}
\hline Nama field & Type & Key & \multicolumn{1}{|c|}{ Keterangan } \\
\hline id_room & int (9) & For & $\begin{array}{l}\text { Foreign key dari table } \\
\text { game_room }\end{array}$ \\
\hline Id_pemain & int (9) & For & $\begin{array}{l}\text { Foreign key dari tabel } \\
\text { pemain }\end{array}$ \\
\hline
\end{tabular}

Gede Humaswara Prathama: Analisa Penggunaan WebRTC dan...

\begin{tabular}{|l|l|l|l|}
\hline & & & $\begin{array}{l}\text { Status hasil } \\
\text { permainan terhadap } \\
\text { pemain (0 untuk } \\
\text { status }\end{array}$ \\
& smallint(3) & $\begin{array}{l}\text { dalam permainan, 1 } \\
\text { untuk menang, 2 } \\
\text { untuk draw dan 3 } \\
\text { untuk kalah) }\end{array}$ \\
\hline
\end{tabular}

\section{B. Proses Pengujian}

Proses pengujian sistem dilakukan untuk melihat hasil yang dihasilkan sistem. Proses pengujian yang dilakukan pada penelitian ini dilakukan pada dua hal antara lain.

1) Latency:yaitu mengukur dan membandingkan latency yang didapat dengan skenario sebagai berikut:

- membandingkan 2 pemain menggunakan websocket dengan websocket dan webRTC.

- membandingkan 3 pemain menggunakan websocket dengan websocket dan webRTC.

- membandingkan 4 pemain menggunakan websocket dengan websocket dan webRTC.

- membandingkan 5 pemain menggunakan websocket dengan websocket dan webRTC.

\section{Jadwal Penelitian}

Jadwal pelaksanaan penelitian dilakukan dari bulan Maret 2018 sampai dengan Agustus 2018 yang diawali dari proses studi literatur sampai dengan penyusunan laporan.

\section{HASIL DAN PEMBAHASAN}

Multiplayer online games ceki berbasis client-server sehingga terdapat 2 bagian pada arsitektur yaitu arsitektur pada server dan arsitektur pada client. Untuk dapat menguji performansi dari websocket dengan websocket + webRTC maka pada penelitian ini dibangun 2 arsitektur yang menjalankan protokol websocket dengan websocket + webRTC.

\section{A. Arsitektur multiplayer online games pada permainan} tradisional ceki

Server pada multiplayer online games ceki secara umum digunakan untuk mempertemukan antara pemain, mencatat game state dan mencatat histori permainan dari masing-masing pemain. Terdapat 4 komponen utama yang ada pada server yaitu Database, middleware, Game room dan game state. Database pada multiplayer online games ceki memiliki hanya 3 tabel seperti pada perancangan yaitu tabel pemain, tabel room dan tabel room pemain. Middleware pada arsitektur ini adalah untuk mengautentifikasi pengguna yang memanggil server dan menentukan data yang boleh diakses oleh pengguna. Game room pada arsitektur ini adalah untuk mempertemukan para pemain pada permainan yang sama dan bertugas untuk menginisialisasikan permainan dengan mengacak kartu serta membagikannya kepada pemain. Game room hanya menggunakan protocol websocket pada 2 arsitektur yang dibangun pada penelitian ini. Pada arsitektur yang hanya menggunakan websocket, game room bertugas juga untuk sinkronisasi data setiap langkah dari pemain. Game p-ISSN:1693 - 2951; e-ISSN: 2503-2372 
state pada arsitektur ini adalah untuk mencatat setiap langkah dari pemain yang ada pada 1 room, jadi ketika ada pemain yang berkoneksi ulang ke dalam room, game state yang bertugas memberikan state terakhir dari permainan. Game state hanya menerima koneksi melalui protocol http pada 2 arsitektur yang dibangun pada penelitian ini. Client pada arsitektur ini merupakan aplikasi yang akan diakses oleh pemain melalui web browser.

\section{B. Gameplay permainan tradisional ceki pada multiplayer online games}

Permainan dimulai dengan menginisialisasi permainan dengan memilih menu create room atau join room, lalu bergiliran masing-masing pemain boleh mengambil kartu dan membuang kartu, hingga mendapatkan hasil dari permainan. Terdapat 2 kemungkinan hasil dari permainan yaitu salah satu pemain menang atau permainan berakhir imbang.

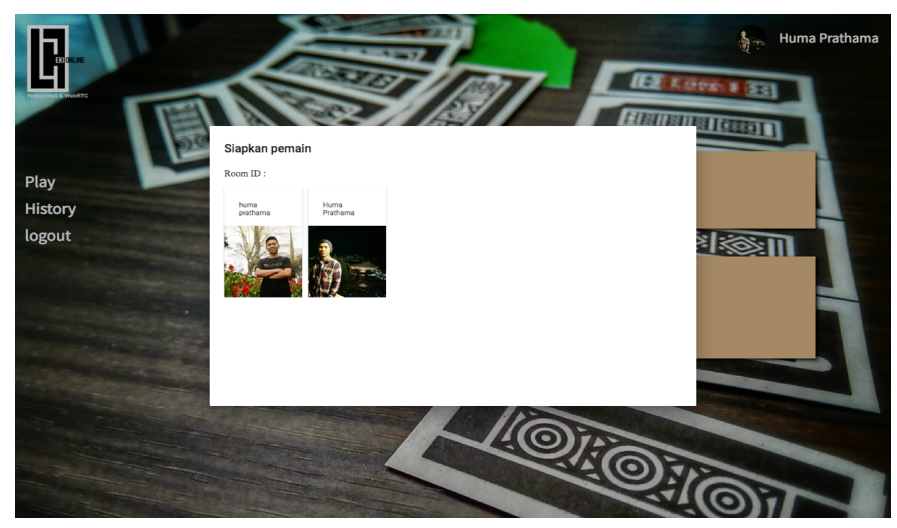

Gambar 3: Tampilan join room

Saat giliran dari 1 pemain, pemain tersebut hanya boleh membuang 1 kartu dan mengambil 1 kartu dari kartu tengah atau dari kartu buangan pemain sebelumnya, kartu yang boleh diambil dari kartu buangan pemain sebelumnya hanya kartu buangan terakhir dari pemain sebelumnya, begitu seterusnya hingga menemukan pemenang atau draw. Dalam kenyataannya lama pemain dalam memilih kartu yang diambil dan membuang kartu tidak ditentukan, namun pada gameplay dari penelitian ini ditambahkan waktu gilir, fitur itu ditambahkan untuk mengantisipasi pemain yang tidak melanjutkan permainan atau meninggalkan permainan terlalu lama, sehingga ketika waktu habis kartu yang diambil dan dibuang akan otomatis dipilih oleh game engine.

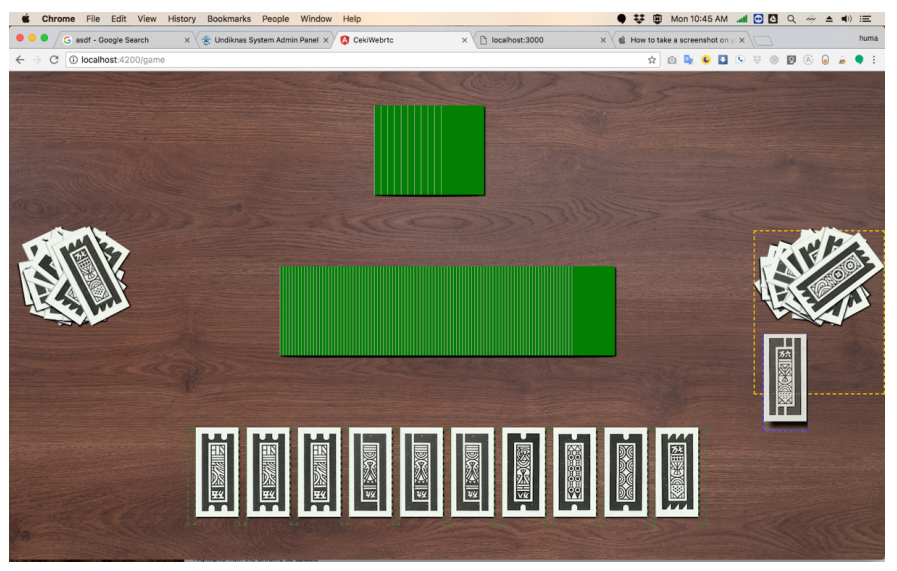

Gambar 4: Tampilan pemain membuang kartu

\section{Aturan Permainan Ceki Online}

Aturan permainan ceki online secara umum masih sama dengan aturan permainan ceki tradisional yang ada namun terdapat aturan baru yang disesuaikan dengan kondisi dimana pemain bisa melakukan kecurangan atau tidak fair play. Beberapa kondisi yang dimaksud adalah saat salah satu pemain tidak melakukan gerakan dalam waktu yang lama atau bahkan meninggalkan permainan saat permainan masih berlangsung sehingga merugikan pemain lain, dengan kondisi seperti ini pada permainan ceki online ini ditambahkan fitur timer untuk membatasi waktu yang dihabiskan oleh 1 pemain pada setiap gerakannya. Lama waktu yang dipilih adalah 1 menit, pemilihan waktu 1 menit yang boleh digunakan pemain untuk melakukan gerakan berdasarkan pada permainan lain seperti permainan MOBA mobile legend yang ketika pemain tidak aktif dalam waktu 2 menit maka pemain akan digerakan oleh game engine, permainan yang lain seperti domino online yang merupakan permainan kartu juga menggunakan timer, rata-rata dari beberapa permainan domino pemain diberikan waktu antara 15-20 detik untuk melakukan gerakan, jika lebih dari itu maka kartu akan digerakan oleh game engine, permainan ceki pada penelitian menggunakan 1 menit adalah dari pertimbangan jumlah kartu yang dimainkan lebih banyak dari kartu domino, model permainan juga lebih kompleks dari domino namun tidak lebih kompleks dari game moba. Terdapat juga kondisi dimana pemain kehilangan koneksi atau koneksi sangat lambat, kondisi seperti ini sangat sulit dihindari dan solusi yang bisa digunakan seringkali merugikan semua pemain dan juga pengembang game, kesulitannya dikarenakan hal seperti ini bergantung kepada koneksi internet yang digunakan pemain, hardware yang digunakan pemain dan hal lainnya yang bisa mengganggu permainan diluar dari arsitektur permainan itu sendiri, maka hal yang bisa dilakukan untuk menjaga permainan tetap berlangsung adalah memanfaatkan timer untuk game engine menggerakan pemain tertentu jika melewati timer yang telah ditentukan pada permainan yaitu 1 menit.

\section{Hasil uji performansi websocket dengan websocket dan webRTC}

Berikut adalah hasil uji performansi yang didapatkan dengan membanding $R T T$ setiap paket dari arsitektur yang menggunakan websocket dengan websocket dan webRTC. pengujian dilakukan dalam 4 tahap, yaitu pengujian terhadap 2 pemain, 3 pemain, 4 pemain dan 5 pemain.

TABEL IV

RANGKUMAN HASIL UJI PERFORMANSI

\begin{tabular}{|c|c|c|c|c|c|}
\hline \multirow{3}{*}{ No. } & \multirow{3}{*}{$\begin{array}{l}\text { Jumlah } \\
\text { pemain }\end{array}$} & \multicolumn{4}{|c|}{ latency } \\
\hline & & \multicolumn{2}{|c|}{ websocket } & \multicolumn{2}{|c|}{ websocket + webRTC } \\
\hline & & $\begin{array}{l}\text { range } \\
(\mathrm{ms})\end{array}$ & $\begin{array}{c}\text { average } \\
(\mathrm{ms})\end{array}$ & $\begin{array}{c}\text { range } \\
(\mathrm{ms})\end{array}$ & $\begin{array}{c}\text { average } \\
(\mathrm{ms})\end{array}$ \\
\hline 1. & 2 pemain & $36-98$ & 41 & $1-3$ & 2 \\
\hline 2. & 3 pemain & $36-52$ & 40 & $1-11$ & 3 \\
\hline 3. & 4 pemain & $37-138$ & 56 & $1-23$ & 7 \\
\hline 4. & 5 pemain & $37-51$ & 40 & $1-13$ & 7 \\
\hline
\end{tabular}




\section{KESIMPULAN}

Simpulan yang dapat diambil dari hasil pengujian adalah Arsitektur permainan pada penggunaan websocket dengan websocket + webRTC menjadi berbeda. Perbedaan ada pada sinkronisasi data, pada websocket sinkronisasi data dilakukan oleh server sedangkan webRTC sinkronisasi dilakukan oleh client yang melakukan gerakan dengan mengirim ke peer yang lain dan ke server. Gameplay dari permainan ceki pada online multiplayer games dengan kenyataan tidak jauh berbeda, hanya ditambahkan aturan-aturan baru untuk menjaga kelancaran permainan, seperti waktu yang diberikan kepada setiap pemain ketika mendapat giliran. Pada rangkuman hasil uji performansi dapat dilihat rata-rata latency yang dibutuhkan untuk sinkronisasi data antara websocket dibandingkan dengan websocket+webRTC sangat signifikan. Pada webRTC latency terendah adalah $1 \mathrm{~ms}$ yang bisa disebut dengan realtime, pada websocket latency terendah adalah 36 $m s$ dimana $36 \mathrm{~ms}$ adalah waktu yang dibutuhkan untuk melakukan ping ke server. dari hasil rangkuman juga dapat dilihat bahwa jumlah pemain tidak berpengaruh pada latency baik pada websocket maupun webRTC. Latency hanya dipengaruhi oleh kecepatan internet yang digunakan. Penggunaan webRTC masih terlalu dini untuk diterapkan ke tahap produksi untuk games, hal ini dikarenakan belum semua platform mendukung dan menggunakan standar webRTC, dimana pada penelitian ini ada beberapa browser yang tidak mendukung penggunaan webRTC dan beberapa browser yang tidak menggunakan standar W3C untuk webRTC.

\section{REFERENSI}

[1] A. Rollings and E. Adams, Andrew Rollings and Ernest Adams on Game Design, New Riders, 2003.

[2] D.Varun Ranganathan, Design Patterns for Multiplayer Card Games. Computer, Communication and Signal Processing (ICCCSP). Chennai: IEEE, 2017.

[3] H. C. Kusuma, Rancang Bangun Aplikasi Massive Multiplayer Online Role Playing Game Berbasis Client-Server dengan Optimaliasi Paket. Electronic computers. Computer science, Surabaya, jul. 2011.

[4] M. Somantri, A. Darmariyadi, Penerapan Pengolahan Paralel Model Cluster Sebagai Web Server. Majalah Ilmiah Teknologi Elektro, [S.1.], v. 6 , n. 1, jan. 2007. ISSN 2503-2372. Available: https://ojs.unud.ac.id/index.php/JTE/article/view/233.

[5] P. L Greco, (2017). HTML5 WebSocket: A Quantum Leap in Scalability for the Web. Retrieved from websocket.org: http://www.websocket.org/quantum.html.

[6] Mozilla Developer Network. (2015). Websockets. Retrieved from MDN web docs: https://developer.mozilla.org/enUS/docs/Glossary/WebSockets.
[7] Yuzo Fujishima, F. U. (2009, Desember 9). Web Sockets Now Available In Google Chrome. Retrieved from blog.chromium.org: https://blog.chromium.org/2009/12/web-sockets-now-available-ingoogle.html.

[8] I. Fette, A. Melnikov, Relationship to TCP and HTTP, RFC 6455 The WebSocket Protocol. IETF. sec. 1.7, Dec. 2011.

[9] K. K. Dev, WebRTC Implementation Analysis and Impact of Bundle Feature, International Conference on Communication Systems and Network Technologies. 5. Gwalior, India: IEEE, 2015.

[10] L. A. Sajjad Taheri, WebRTCBench: A Benchmark for Performance Assessment of WebRTC Implementations, Embedded Systems For Realtime Multimedia (ESTIMedia). 13, Amsterdam: IEEE, 2015.

[11] W3C, WebRTC 1.0: Real-time Communication Between Browsers. Available: https://www.w3.org/TR/2008/WD-html520080610/comms.html\#tcp-connections, 2018. 
[ Halaman ini Sengaja di Kosongkan ] 